\title{
Historical Foundations of Science and Technology in Egypt
}

\author{
Nagwa Nawar \\ Department of Chemistry, Faculty of Science, \\ Mansoura University, Egypt
}

\section{Doi:10.5901/ajis.2013.v2n6p67}

\section{Abstract}

This paper represents a brief description of the historical foundations of science and technology in Egypt. Since the ancient Egyptians were masters in metallurgy and were known throughout the ancient world as expert goldsmiths up to the twenty first century.

Keywords: historical foundations of science and technology in Egypt.

\section{Introduction}

For millennia, Egypt has made significant contributions to the progress of mankind and to the advancement of society. As a cradle of civilization and a beacon of knowledge, Egypt was a leader in scientific discoveries and innovations that defined the foundations of many fields including astronomy, chemistry, medicine, and of course engineering whose supremacy can still be seen today in the majestic architecture of the Pyramids and Karnak. The ancient Egyptians were enterprising people: they left many impressive monuments such as pyramids and temples; they were among the first nations to develop metallurgy, out of a need for tools; they were the first to extract copper from its ores and to extract gold by melting; they were experts in jewelry and gold working as is seen from the world-famous death mask of Tutankhamun. ${ }^{1}$

\section{Ancient Egyptian Urban Planning and Infrastructure}

One indication of the Egyptians' advanced civilization is doubtless their knowledge of architecture and engineering (Figure 1).

Figure 1

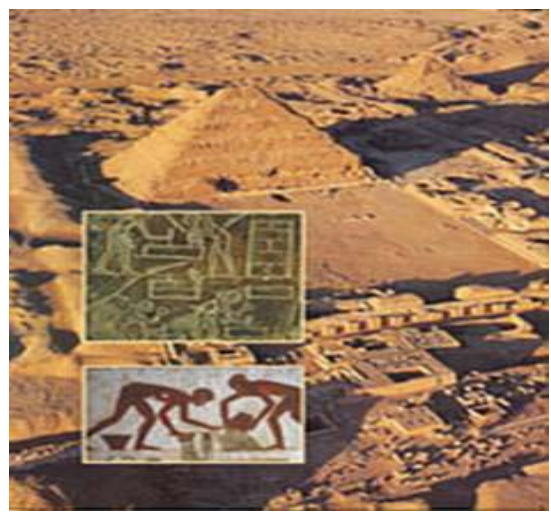




\section{Advanced Metallurgy in Ancient Egypt}

Figure 2 represents advanced Metallurgy in Ancient Egypt where $(1,2)$ represent finely worked pectorals of the king, crafted of gold, silver and semi-precious stones; (3) represents a pair of finely crafted sandals and (4) represents a small, long-spouted pitcher made of hard gold still maintains its strength and brightness.

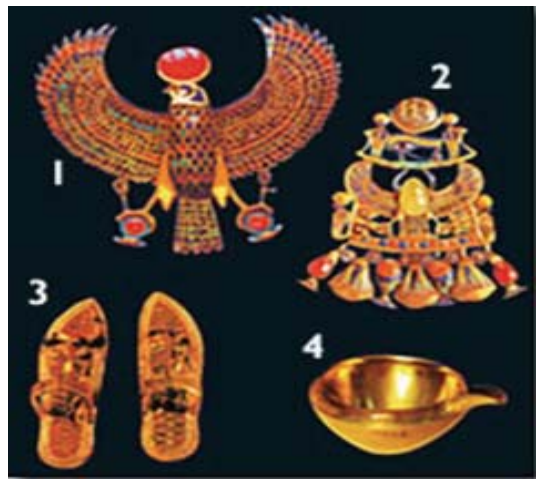

Figure 2

\section{Ancient Egyptians' Achievements in Textiles}

Figure 3 represents examples of linen, dating back to Ancient Egypt.

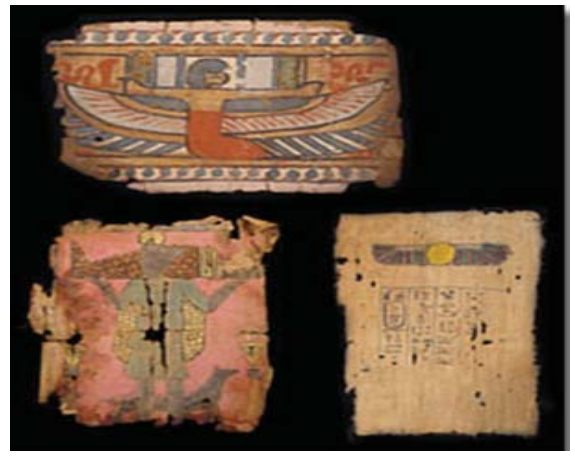

Figure 3

\section{Ancient Egyptian in medicine}

Figure 4 represents the body of the Egyptian Pharaoh Tutankhamen was preserved inside two coffins, one inside the other. ${ }^{3}$ 


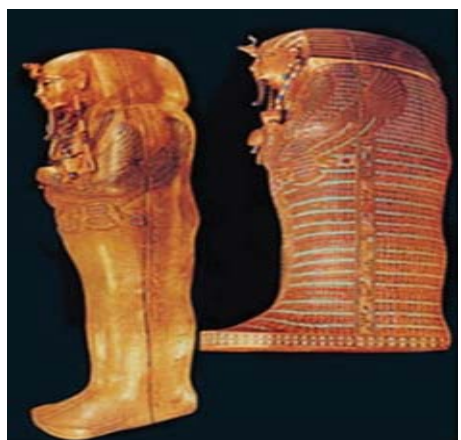

\section{Figure 4}

Figure 5 represents the Egyptians' mummification techniques demonstrate that they possessed advanced medical knowledge.

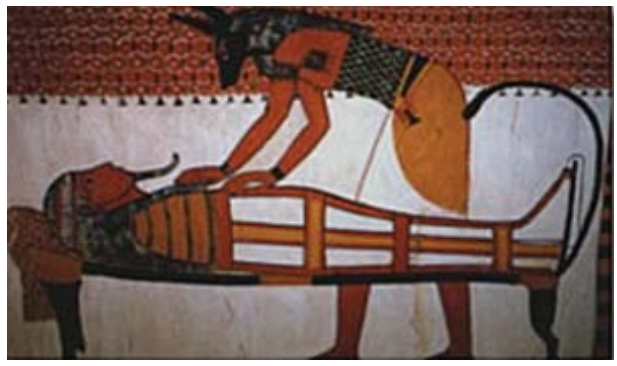

\section{Figure 5}

\section{An Advanced Level of Mathematics}

Indeed, Egypt is a living testimony to the nexus between the power of knowledge and the progress of society.

Figure 6 represents the Rhind Papyrus

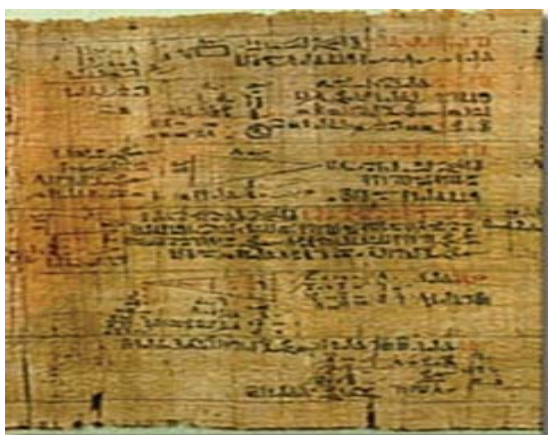

Figure 6 


\section{Ancient Egyptian mining}

In Egypt generally an adjunct of gold, silver was in the very early days of metal working rarer and dearer than the gold itself. The copper used in Egypt was seemingly mined in the eastern desert or Sinai as shown in Figures 7, 8.,

In addition to copper, which was mined in the eastern desert between the Nile and the Red Sea, iron was known in Egypt from a very early period and came into general use about 800 B.C. Also, the introduction of bronze (Figure 9) was a huge improvement in tool and weapon manufacture. Bronze is an alloy of copper and of about $4 \%$ tin. It is harder than pure copper

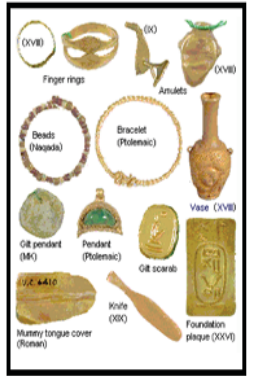

Figure 7
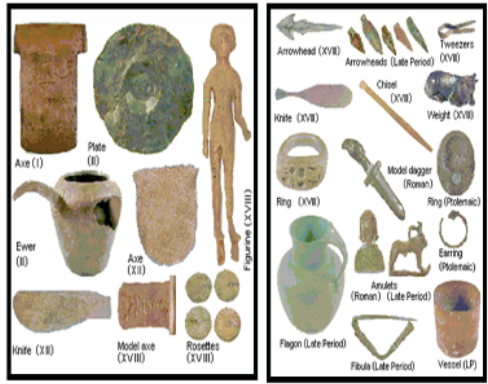

Figure 9

\section{Egyptian Alchemy}

Chemistry as a field has its root in the name of the ancient land and the art of the discipline was in full use there for the making of glass, bronze and metal chemistry. Even the synthesis of new compounds was apparently known at the time. Today we consider chemistry to be a science, but its roots, back in Ancient Egypt, lie in art and the creation of synthetic pigments.

\section{Color Technology in Ancient Egypt}

Our knowledge of Ancient Egyptian color technology comes from a handful of ancient papyri. ${ }^{7}$ The most important, held in the Leiden collection and known as Papyrus $X$, contains the recipes for making pigments. Another held by the Stockholm collection contains recipes for dyeing and making artificial gemstones. There were three basic groups of synthetic pigment used in Ancient Egypt: powdered glass, corrosion products, or those altered through the application of heat. Figure 10 represents modern Alternatives for Ancient Egypt Colors.

They were experienced in chemical technologies, such as making wine, beer, honey, pottery, and glass Figure 11. The paintings left behind in their tombs attest to an intricate knowledge of inorganic colored salts used as paint pigments. They were known in the ancient world as expert dyers and were ahead of most nations in the production of cosmetics, perfumes, and pharmaceuticals. $^{8-12}$ 


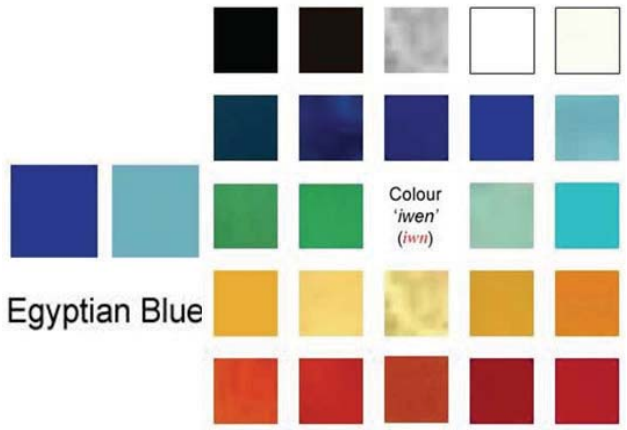

Figure 10

Figure 11

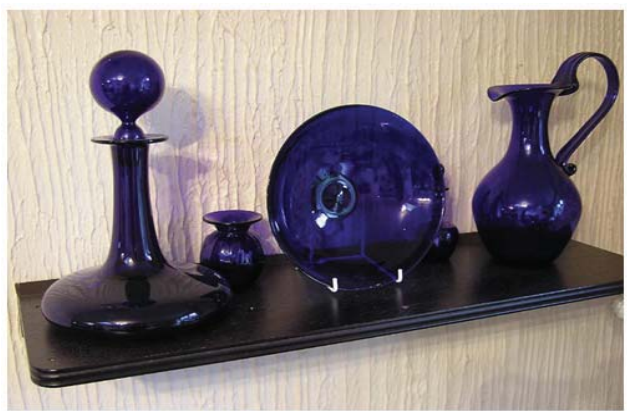

\section{Cosmetics in Ancient Egypt}

A recent report by a team of French scientists, the eye cosmetics used at the time of Nefertiti contained a man-made lead compound that helped treat or prevent eye disease (figure 12). ${ }^{13}$

In Alexandria some two thousand years ago, the library and museum constituted a center of gravity for scholars including Euclid, Archimedes, Hipparchus, and Hepatia. The Library of Alexandria was a center of knowledge that gathered scholars from all over the world (Figure 13).

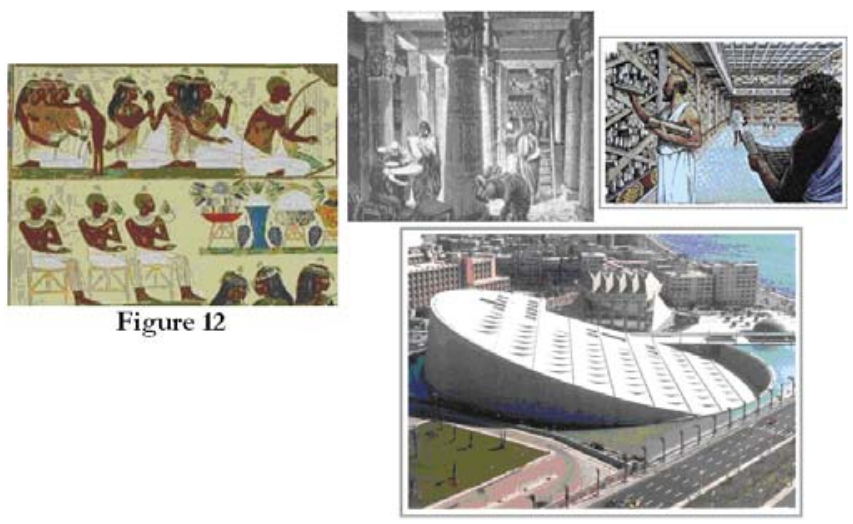

Figure 13 


\section{Islamic civilization}

Nearly a thousand years ago, the Islamic civilization spread, along with its scientific achievements, to Europe and Asia and there is no doubt that this contact paved the way to the European Renaissance. Science blossomed and Renaissance men emerged. The Muslim scientist Ibn alHaytham, known to the West as Alhazen, who lived ca. 965-1040 CE in I raq and Egypt, made major contributions to the science of imaging and vision. ${ }^{14}$

Ibn al-Haytham concepts were later used by Descartes, Newton, and Leonardo Da Vinci and his experiments with light in what is called "the dark room," or hogra al-mozlema, later known as camera obscura, formed the basis of modern photography (Figure 14). The making of useful knowledge by Ibn al-Haytham, Ibn Rushd (the polymath philosopher known in the West as Averroes), Ibn Sina (the foremost physician of his time, known as Avicenna), and al-Khawarizmi (whose Latinized name, Algoritmi, inspired the terms algorism and algorithm) forged centers of enlightenment in Baghdad, Cairo, and Cordoba. A millennium ago, Al-Azhar was established as a knowledge institution (Figure 15), ahead of universities in Europe. Al-Hazen's work formed the basis of modern photography.

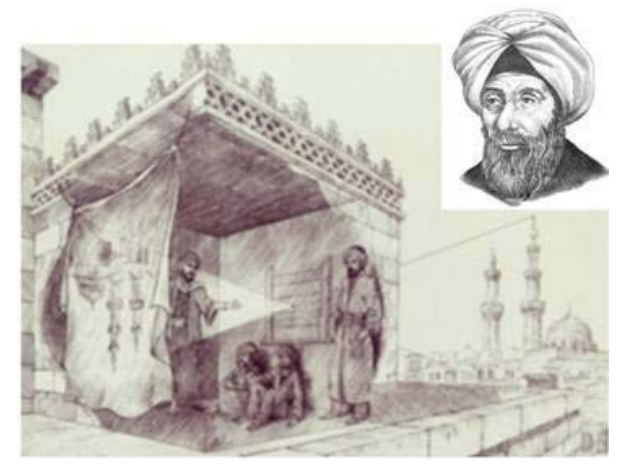

Figure 14

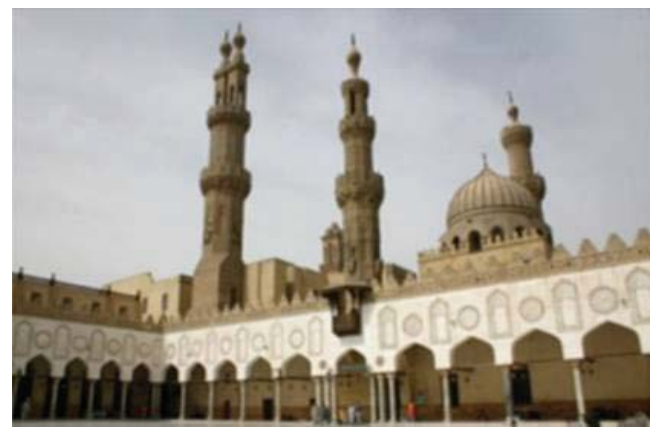

\section{Figure 15}

Only two centuries ago under the visionary leadership of Mohammed Ali, Modern Egypt underwent a renaissance in education, culture, and industry (Figure 16). 


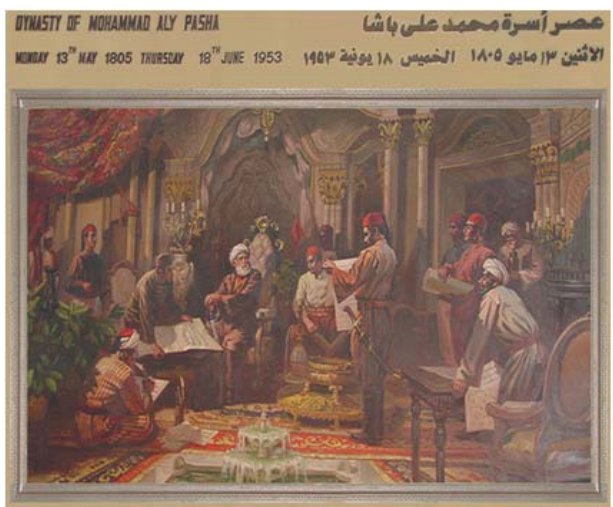

\section{Figure 16}

Egypt again became a regional industrial and military superpower, and reforms in education led by Rifa'a al-Tahtawi (1801 - 1873) and his followers were crucial elements that brought about the renaissance (Figure 17).

\section{Figure 17}

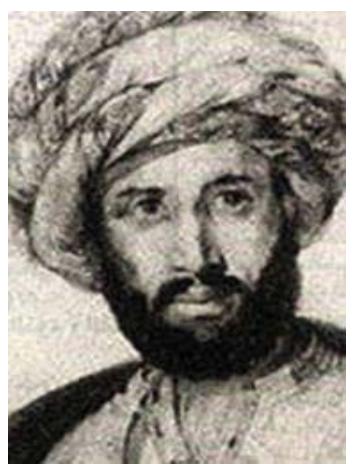

In the years to follow, Cairo shone as the center for studies and cultural activities in literature, arts, science, and media. Egyptian universities graduated leaders in all fields and their works influenced Arab society at large. We still live with the echoes of their contributions, from the writings of Taha Hussein, Naguib Mahfouz, and Ali Moustafa Mosharafa, to the songs and films of Umm Kulthum, Abdel Wahab, and Faten Hamama (Figure 18).

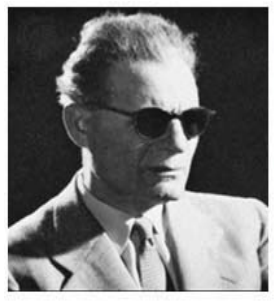

Taha Husayn 1889 to 1973

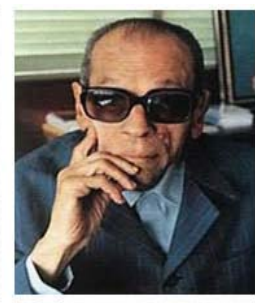

Naguib Mahfouz Ali M. Mosharafa 1911 to 2006

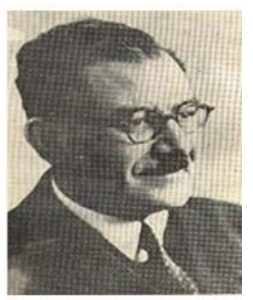

1898 to 1950

Figure 18 
In the twentieth century Egypt established democratic governance and built powerful institutions in various sectors, including Cairo University, Al-Ahly and Misr Banks, Al-Ahram newspaper, and industries such as textiles and motion pictures. With this advanced status, Egypt attracted and educated future generations of Arabs. In the present, the contributions of Egypt and the Arab world to science and technology, and to knowledge-based economic productivity, are modest if not minor on the global level. This has led to the export of skills in what is known as the phenomenon of brain drain; i.e., the migration of many able scientists to Western countries and the import of technology from Western and other advanced nations. Both the brain drain and the lack of a solid scientific base in Egypt and other Arab countries have limited their participation in the global market. The Arab world is rich in human and financial resources and there should be no major obstacles preventing the building of a world-class scientific base. This knowledge base is vital for the future of the Arab people, not only for economic prosperity but also for their enlightenment and influence in world affairs. Now, the choice is ours: either to become three hundred and fifty million people of the cave, ahl al-kahf, or three hundred and fifty million people of the cosmos, ahl alkawn.

\section{Egypt - Science and Technology}

Founded in 1971, the Academy of Scientific Research and Technology in Cairo is the national body responsible for science and technology. Egypt also has 12 specialized learned societies in the fields of agriculture, medicine, science, and technology. The National Research Center, also in Cairo, carries out research in pure and applied sciences. Located in Cairo are museums devoted to agriculture, geology, railways, and marine technology. In addition to polytechnic institutes in Cairo and Mansoura, Egypt in 1996 had 13 universities offering courses in basic and applied sciences.

\section{Science, Technology and Innovation (STI) System in Egypt}

Egypt is aiming to achieve a high standard of scientific achievement; this ambitious aim is built on a well founded research structure and a vast manpower resource of critical mass. ${ }^{15}$ The recent legislations and policies which were in conformity with the development of Egyptian civilization in the modern era had an effective impact on science, technology and innovation (STI). The major legislation in this decade included the following:

1. In 2002, the Law No. 82 for the protection of intellectual property rights was issued to support the creative values and to encourage the technological innovation, according to the international developed standards, including the protection of new forms of intellectual property rights.

2. In 2005, the Law No. 2 was issued to double the monetary value of the state prizes.

3. In 2007, President Mohamed Hosni Mubarak issued a presidential decree No. 218 to establish science and technology development fund (STDF) to support the scientific research and technological development prioritized by the Higher Council for Science and technology (HCST).

4. In 2008, President Hosni Mubarak issued a presidential decree forming the HCST. The council's board includes minster of higher education and state for scientific research and a galaxy of Nobel laureates, prominent Egyptian scientists in Egypt and Egyptian in Diaspora. The Council is chaired by the Prime Minister to promote and enhance science and technology development.

5. In 2008, President Hosni Mubarak issued Law No. 117 to double (for the second time) the monetary value of the state prizes. In 2008, the program for research and development and innovation was established to promote economic growth and international 
competitiveness of Egypt by improving the performance of research and development and innovation.

Several initiatives have been taken as an attempt to strengthen the R\&D system in Egypt and to lay the ground for developing an innovation system; this includes the creation of science parks, incubators and technology valleys.

In conformity with the main aim of the research policy to reform S\&T activities in Egypt, President Mubarak announced the period 2007-2016 as a "Decade for Science \&Technology", the purpose of this decade is to clearly extend the Egyptian government commitment to $S \& T$, enhance scientific cooperation with scientifically advanced countries and strengthen Egypt's scientific and technological base.

The Egyptian Decade of S\&T (2007-2016) was announced in 2007. STI activities were directed to specific priority sectors and technological areas, which are important for the competitiveness of the economy and for specific national policies. The identified priority areas by HCST are; renewable energy, water resources, health, food and agriculture, space technology, ICT and Socio-economic sciences and humanities.

Chart 1 shows the current structure of STI system in Egypt after restructuring. The STI system consists of HCST, MOSR, ASRT and STDF.

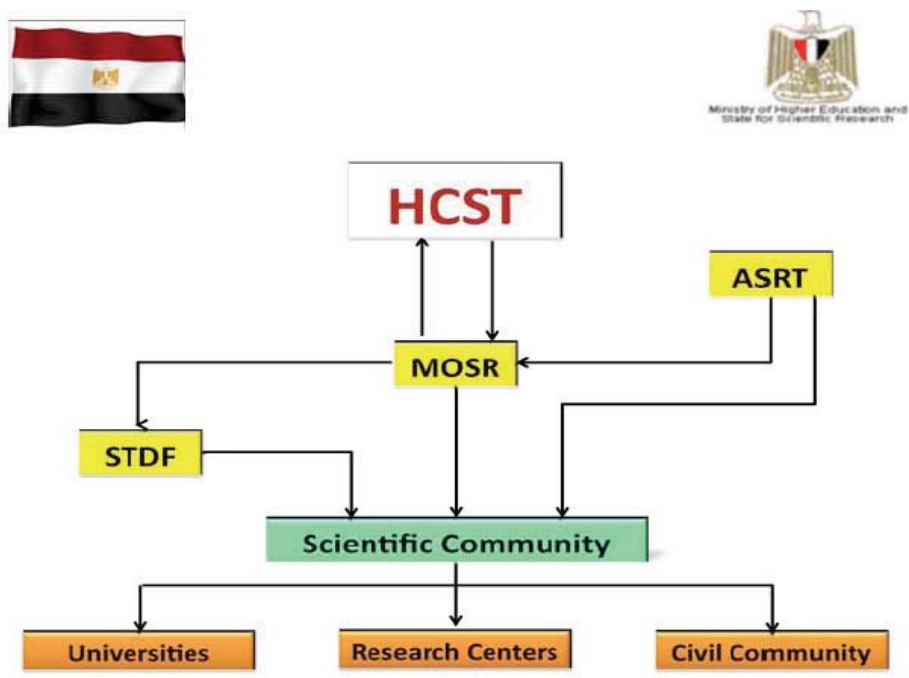

\section{Chart 1}

\section{Academy of Scientific Research \& Technology (ASRT) House of Expertise}

The Academy of Scientific Research \& Technology (ASRT) Figure 19, was established in September 1972 by the Presidential Decree No 2405 as the national authority responsible for science \& technology in Egypt. ASRT is a non-profit organization affiliated to the ministry of scientific research. In 1998 the Presidential Decree No 377 was issued to define its mission, function and activities. ASRT is the Egyptian house of expertise. It brings together outstanding Egyptian scientists and experts from universities, research institutions, private sector, NGOs, policymakers and prominent Egyptian scientists in Diaspora, to deliberate country problems, propose and carry out scientific studies and future strategic basic plans to tackle these problems. 


\section{Figure 19}

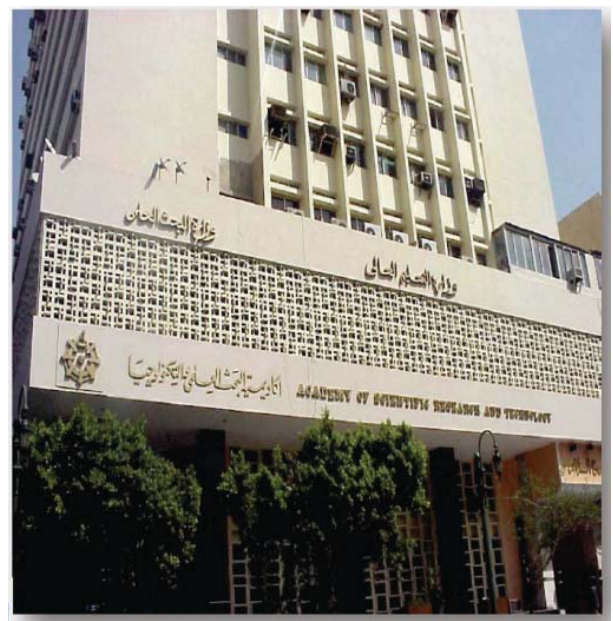

ASRT is adopting a comprehensive plan for developing Egyptian S\&T to support relevant national ministries and research institutions to create an integrated system of scientific research together to increase the number of trained scientists in Egypt, and give science a leading role in the country's development and knowledge based economy. ASRT also promotes and encourages female and youth participation in S\&T, in scientific leadership. The vision of ASRT is to be effective and reliable national think tank for the service of Science, Technology and innovation (STI) in Egypt, as the main pillar of knowledge-based economy. The mission of ASRT is to create an enabling and stimulating environment, to maximize the outcomes of STI, through promotion, coordination, assessment, encouragement and appreciation of excellence in STI.

ASRT is responsible for performing the following functions:

1. Conducting future studies and strategic plans to tackle country problems

2. Strengthening cooperation with international counterparts (Academies, STI institutions, IAP, .. etc)

3. Raising the awareness and promotion of scientific culture $\&$ thinking

4. Assessing S\&T (ST indicators)

5. Supporting and appreciating excellence in STI.

6. Establishing and taking care of virtual multi institutional centers of excellence and research consortia in advanced and interdisciplinary basic and applied research.

7. Bridging the gap between scientists and private sector.

8. Encourage the complete cycle of innovation.

9. Enhancing the participation of youth and women in STI system.

i. Egyptian Young Academy of Science (EYAS).

ii. Egyptian Woman Academy of Science (EWAS).

\section{Pillars of ASRT}

ASRT implements its duties through fifteen specialized scientific councils, five regional development centers, virtual research consortia and networks, TV channel, monthly scientific magazine for public, national committees, scientific societies, patent office, and regional office for ethics and national network for information (ENSTINET). 


\section{Specialized Scientific Councils (SSCs)}

SSCs are the main implementing arm of ASRT, as house of expertise and think tank. In 2009, the structure of the SSCs were developed in order to support the role of the Academy as a house of expertise that provides trustworthy scientific advices, future studies and strategic plans on important public issues to the policy makers and the community with the aim of serving the Egyptian community through fifteen specialized councils in the basic and applied research, engineering, health, food and agriculture, environment, energy, industry, space, ITC, water, economy, humanities, ethics, culture and strategic planning.

The SSCs are responsible for performing the following functions:

1. Identifying and promoting the best practices in S\&T to provide all possible assistance to the development of S\&T in Egypt.

2. Enhancing the integration of scientific research \& technology planning with the overall national development plans.

3. Drawing the policies that ensure the closest links between the $R \& D$ community and the national development priorities according to the field of specialization of each research council.

4. Planning technological development programs that fit the national economic and social objectives and the marketing of technical know-how. R\&D management.

5. Conducting studies in the fields of Modern and Future Sciences and Basic Academic Research which can be translated to final products and services, focusing on thematic areas of national development priorities.

6. Evaluating the status of $S \& T$ in the different fields of researches.

The roots of the Intellectual Property in Egypt go to 1951 by the law 132/1949. The New Law 82/2002 protects the utility Models, Layout-Designs for Integrated Circuits and Undisclosed Information. EGPO is the sole national office responsible for registering and issuing patents. EGPO is accredited by WIPO as regional searching authority and plays key role in technology transfer, IPR protection and creation of enabling environment for STI-based business and investment. The EGPO represents Egypt in:

1. WIPO since 1975.

2. Paris convention since 1951.

3. Strasbourg agreement since October 1975.

4. TRIPS agreement since 1995 .

5. PCT Treaty since June 2003.

In September 2009, during the international meetings of the General Assembly of the World Intellectual Property Organization (WIPO), the Egyptian Patent Office was accredited as an International Searching Authority and International Preliminary Examining Authority (ISA/IPEA) under the Patent Cooperation Treaty (PCT), and it is currently authorized to accept patents applications from all over the world.

The EGPO is responsible for performing the following functions:

1. Developing property legislations, utility models, lay-out designs of integrated circuits, restricted information, relations, commercial data, geographical indications, industrial graphics and designs, and copyright.

2. Providing the Egyptian users with the necessary patents information relevant to various development activities.

3. Registering patent application for the local \& foreign inventions.

4. Granting and issuing patents to protect the rights of the Egyptian \& foreigner inventors.

5. Collecting the foreign patent applications and classifying it to be easily accessible to examiners and users. 
6. Transferring the technological information from the patents all Over the world and provide it to the specialists in order to develop their works and develop the local industries.

7. Supporting the participation of inventors in exhibitions and honors.

8. Monthly Publish the official patent gazette which includes filed, accepted application, granted patents done applications and patents.

\section{Innovation @ invention Development Sector (IIDS)}

IIDS is a member of the International Federation of Inventors Associations (IFIA) Figure 20. It promotes the transfer of technical know-how and granted patent, invention and innovation through marketing of valuable invention. IIDS is aiming at pushing forward process of developing national technology through linking the scientific sector with the R\&D units in production and services sectors. IIDS highlights the advantages of valid innovations and inventions, it contacts the industrial institutions and others to assess their needs of scientific and technological research, which would yield practical results that, could be successfully implemented and marketed. It makes and develops the prototypes of selected patents and carries out semi-industrial experiment. It cooperates with the patent office that provides it with granted patents to be marketed to reach the final end user. IIDS participates in various exhibitions to expose the developed inventions.

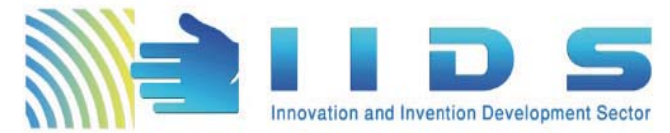

\section{Innovation \& Invention Development Sector (IIDS)}

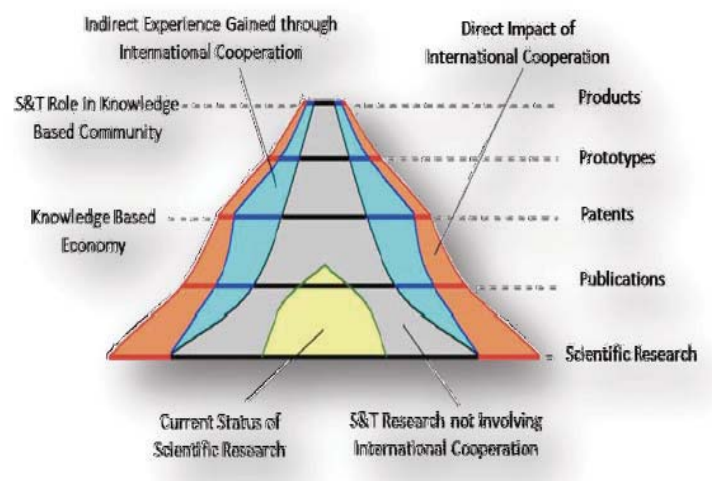

Figure 20

The structure of research and innovation activities in Egypt is presently undergoing significant changes as shown in Chart 2. 


\section{Chart 2}

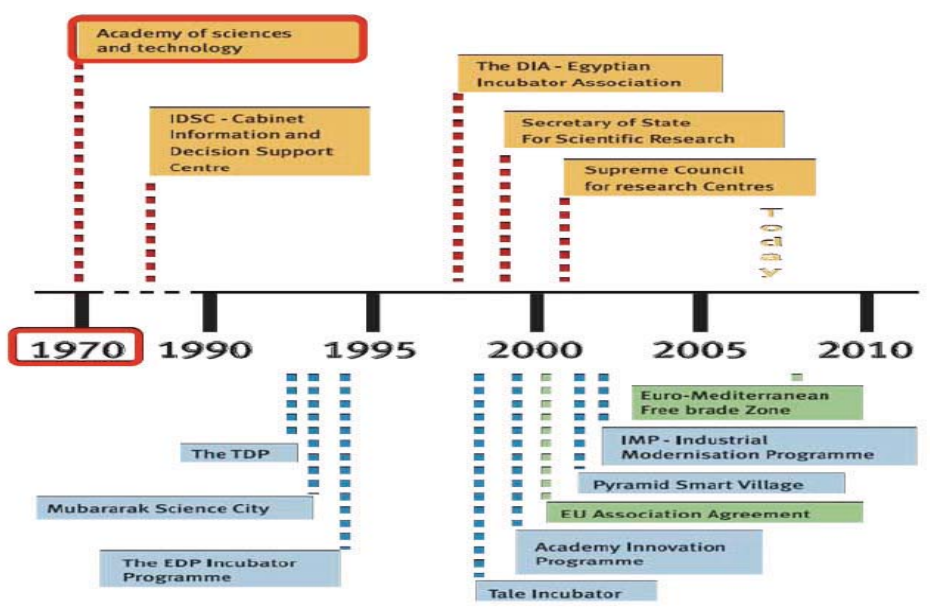

The areas Targeted by Technology Development $\&$ service sector for SMEs are:

1. Developing and updating a general policy framework for SMEs development in Egypt.

2. Developing operational definitions for SMEs.

3. Enhancing the access of SMEs to financial services.

4. Procurement

5. Regulatory reform to reduce the cost of compliance with regulations.

6. Promotion for SMEs

\section{The Science and Technology Center (STC)}

STC gives Egyptian researchers the opportunity to collaborate with foreign colleagues, widen research perspectives and experience, to exchange ideas, to be recognized in the international arena, to gain information and knowledge of techniques that will stimulate and advance Egyptian research, and to be involved in large international projects.

STC manages technical and financial affairs of the following programs:

\subsection{National Strategy for Genetic Engineering and Biotechnology}

The program started in 1996; to meet the strong and urgent need for a solid body to fund and support the use of biotechnology in developing national resources; and maximizing economic, social and environmental benefits. The aim of the program is to create continuous national innovative capacities capable of developing added values, which maintain competitiveness in local and global markets for increasing number of products and services depending on modern biotechnologies.

- Number of funded projects is 106 with a total fund of $18,718,452$ EGP.

- Number of Phase II projects 14 with a total fund of 4, 590, 000 EGP.

- In addition to 3 Pilots at: The National Research Center - Mubarak City for Scientific Research - Technological Applications -Mansoura University with a total fund of 20.4 million EGP.

- Total number of projects 109.

- Number of researchers 727.

- Number of patents 4 . 
- Number of thesis 22.

- Number of publications 95.

\subsection{Egypt - France J oint Fund (IMHOTEB)}

The aim of the program is to enhance the cooperation between Egyptian and French researchers affiliated to the governmental research institutes in both countries.

\subsection{Egypt - Greece Joint Fund}

\subsection{US-Egypt Joint Fund}

The US-Egypt S\&T (S\&T) Joint Fund was established under an Agreement between the Government of the United States of America and the Government of the Arab Republic of Egypt on S\&T Cooperation to strengthen scientific and technological capabilities between Egypt and the United States.

\subsection{MENA-Sweden Research Link Program}

The aim of the program is to foster research ties between researchers in Sweden, on the one hand, and researchers in Asia, the Middle East and North Africa region (MENA) and South Africa on the other. The key condition for the Swedish Research Links Program is that researchers from the countries involved must submit joint applications on projects of mutual interest.

\subsection{Focal Point of the International Center of Genetic Engineering and Biotechnology}

The Academy of Scientific Research and Technology is the focal point of the cooperation with the International Center for Genetic Engineering and Biotechnology ICGEB.

\subsection{Transfer of Technical know-how}

Started in 1996 after the end of the agreement between The Academy of Scientific Research and

Technology and the American Agency for International Development "USAID". Main Task: Marketing and transferring the technical know-how resulted from the projects contracted and executed under the previous agreement in the following sectors:

\subsubsection{Water Purification Sector}

The transfer of know-how for developing and implementing 132 plants for drinking water purification

\subsubsection{Drainage Sector}

The transfer of know-how for implementing 8 projects.

\subsubsection{Industry Sector}

The transfer of know-how for the production of spray paint roads. 


\section{Scientific \& Cultural Relations Sector (SCR)}

The (SCR) sets up the policies and plans to strengthen the relationship between the Egyptian Science \& Technology community and institutions and the counterpart international organizations to disseminate the culture of $S \& T$ to encourage the innovation and the inventions in collaboration with the civil society and the relevant authorities of scientific research and culture. ASRT aims to develop a spirit of creativity and scientific thinking encouraging community awareness to develop the passion for S\&T in the Egyptian children and youth through scientific competitions and the establishment of science clubs models and science museums and traveling exhibitions to promote scientific culture.

SCR is responsible for performing the following functions:

1. Supporting the activities of scientific unions and societies in order to play an effective role in promoting scientific research and technology.

2. Preparing and follow-up the implementation of S\&T cooperation agreements on the global, regional, multi-lateral or bilateral levels. It is also responsible for fostering the activities of the local NGO's in the fields of S\&T.

3. Developing programs to spread knowledge for various categories in the society through Al-Manara channel.

4. Issuing a series of simplified scientific books, El-Elm magazine (Science magazine) that simplifies scientific facts and demonstrates how S\&T provide better services and develop the socio economic welfare of the society; also, SCR organizes scientific seminars and lectures on scientific topics related to life of individuals.

\section{Regional Development Centers (RDCs)}

RDCs are focal points (satellites) for The ASRT in the different regions of the country, in order to spread the activities of ASRT countrywide. RDCs support the ASRT to carry out its role in the dissemination of scientific culture and to stimulate innovation, invention and community development, in collaboration with civil society and local authorities.

RDCs are equipped with various facilities:

1. Conference and meeting rooms as well as training rooms.

2. Laboratories.

3. Science Museums.

4. Libraries.

5. Exhibitions for development through research projects in various regional fields.

6. RDCs support the implementation of the main duties of ASRT to bridge the gap between scientists and stakeholders.

7. Conducting applied and basic research to generate a continuous flow of technologies that help increase productivity.

8. Transferring of new technologies to the community.

9. Developing Human capital as a continual process.

10. Upgrading technology transfer channels.

11. Applying the findings of S\&T developed abroad.

12. Studying the establishment of incubators models pertaining to the real needs and economical and social situations.

The 5 regional centers are:

1. The Delta Regional Research Center, Tanta

2. The New Valley Regional Development Center, Al-Kharga City

3. The Suez Canal Regional Development Center, Ismailia 
4. The Zagazig Regional Development Center, Sharqia

5. The South Upper Egypt Regional Development Center, Sohag

\section{The Egyptian National Scientific \&Technical Information Network (ENSTINET)}

ENSTINET provides IT and marketing services to raise information awareness and manpower development. Its objectives are to assist Egyptian problem solvers and decision makers to access and apply quality data and relevant, current information to development. The vision of ENSTINET is to become the national information service facility equipped with the latest information Technology, run by the best staff members who render the most efficient services to the scientific community. The mission of ENSTINET is to bring knowledge to bear on human problem solving for the socio-economic development of Egypt. ENSTINET provides various services:

1. Video conferences Facilities.

2. Databases.

\section{Prizes and Fellowships}

One of the main and unique roles of the ASRT is to encourage and appreciate excellence in STI. The ASRT annually awards State Prizes that were established by Prize Legalization PL 37/1958 (recently amended by PL 24/1998) which are the following:

1. El Nile Prizes.

2. State - Merit Prizes.

3. State - Excellence Prizes.

4. State - Encouragement.

\section{International Cooperation in Science \&Technology}

Cooperation in S\&T can take various forms, including joint science projects, sharing of information, conferences, building and sharing joint laboratories, setting common standards for R\&D, and exchange of expertise.

International cooperation advantages include:

1. Access to new knowledge, foreign skills and training opportunities that may not be available at the national level.

2. Exchange of scientific publications and periodicals.

3. Avoiding the costs of duplication of research.

4. Enrichment of political and social relations between countries.

5. Opportunities to establish multidisciplinary research activities and teams.

6. Favorable basis for international funding.

\section{The Decade for Science and Technology}

In 2006, President Hosni Mubarak, declared (2007-2016) the Egyptian Decade of S\&T aiming at enhancing S\&T in Egypt and establishing a "Knowledge-based Economy" in Egypt. The decade is shaped into a successive years of S\&T cooperation with various countries/regions around the world. 2007 was the year of S\&T with Germany, followed by Japan in 2008, Italy in 2009 and France in 2010. 


\section{ASRT and Youth}

Education reform is the gate to the $S \& T$ integration of the academic, university and industrial science of Egypt to promote the all-round development and efficient interaction between science, education and culture, and to pursue a unified scientific and technical policy in the country. ASRT is encouraging young generation to contribute in the field of science, its mission is:

1. To help graduating students gain access to training, funding, information, equipment, and supplies that may better meet the needs of their research projects at Egyptian national universities

2. To encourage young scientists by creating opportunities for Egyptian researchers to develop their professional skills through workshops and training programs, as well as offering funds for research projects.

3. To develop human resources through scientific interaction and reduce the international brain drain by providing the necessary requirements to stay in Egypt.

4. To establish an annual science competition for young people.

5. To support the young researchers by supporting their contribution in the international conferences and workshops inside Egypt and abroad.

\section{Universities in Egypt}

Universities are social institutions that impart knowledge, train researchers, scientists and specialists, inculcate self-esteem, forge a solid national identity, and teach people about their rights. Sorrowfully, several decades of tyranny in Egypt have left the Egyptian universities in ruin. The decline of education in Egypt has been part of the decline of almost all aspects of life. The poor quality of university and pre-university education systems has posed major hurdles to the social, economic and political development of the country. ${ }^{16}$

\section{Zewail Foundation for Science and Technology}

The concept of Zewail City of Science and Technology organized in 1999. Dr. Ahmed Zewail presented the idea and the road map for the Project to then-President Hosni Mubarak on the occasion of Egypt's celebrations of Zewail's Nobil Prize in Chemistry Shortly after this meeting, 300 acres were assigned to what was then called the Zewail Fundation for Science and Technology. The cornerstone was laid on $1 \mathrm{~J}$ anuary 2000 in the presence o then-prime Minister (P) Atef Ebeid in 6th of October City just outside Cairo. Ebeid appropriated a building to the Project in Cairo's Garden City for the board and administration offices. ${ }^{17}$

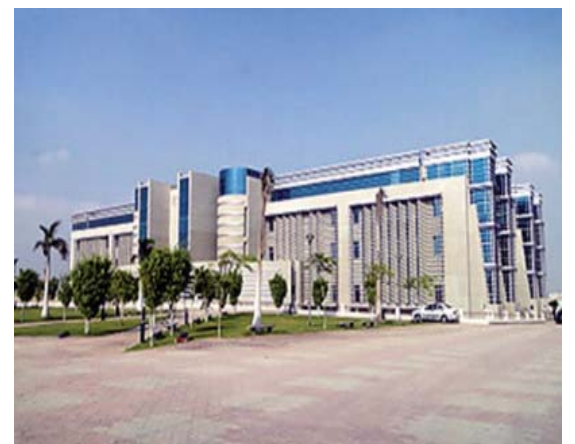

Figure 20 
Zewail Foundation for Science and Technology will catalyze the transition for acquiring modern sciences of today and tomorrow. The 20th Century witnessed revolutions in science and technology that transformed the world. These discoveries and innovations came about as a result of a strong foundation in basic research, the science base, and with scientists working in an atmosphere conductive to attracting creative and independent minds. Examples are numerous: the laser and transistor were the fruits of curiosity-driven basic research, and now they constitute a trillion-dollarplus world market. The Technology Pyramid is a technology park that will constitute the area of confluence between $R \& D$ and the market. The Pyramid has two primary functions. It will provide gifted graduates and technology entrepreneurs the opportunity to incubate and develop new technologies and industries. Zewail City of Science and Technology will provide some financial assistance and appropriate space on a contractual basis to enhance the level of entrepreneurship and aid in the establishment of new industries.

What is going on now in the 21st Century has redefined the meaning of time and distance (Information technology). We can communicate with other planets in minutes, manipulate matter at the nanometer and femtosecond scales. From the infinitely small world (Nano science and nanotechnology), to the extremely large (cosmology), and to the world of complexity (life science), there is no doubt that new innovations will emerge, and knowledge-based societies will have the lion's share of productivity and progress.

\section{References}

http://en.wikipedia.org/wiki/Egyptian_astronomy http://www.thestoneage.org/stone_age_02_b.php

Edwin Smith papyrus (Egyptian ${ }^{-}$medical book). Britannic.com. Retrieved on 2011; http://www. britannica.com/EBchecked/topic/179901/Edwin-Smith-papyrus

http://en.wikipedia.org/wiki/Moscow_Mathematical_Papyrus

http://www.researchgate.net/publication/231268814_Chemistry_in_the_Time_of_the_Pharaohs

Williams, K. R. J. Chem. Educ. 2000, 77, 300.

http://en.wikipedia.org/wiki/Egyptian_blue

Fathi Habashi. Researches on Copper. History \& Metallurgy. Quebec City, Canada: Métallurgie Extractive Québec, 2009.

http://works.bepress.com/fathi_habashi/87

Habashi, F. From Alchemy to Atomic Bombs; M_etallurgie Extractive Qu_ebec, Enr.: Qu_ebec, 2002, 47100.

Ogden, J. In Ancient Egyptian Materials and Technologies; Nicholson, P. T., Shaw, I., Eds.; Cambridge University Press: Cambridge, 2000, 148-173.

Leicester, H. M. The Historical Background of Chemistry; Dover Publications, Inc.: New York, 1971, 5-45.

Lucas A. "Cosmetics, Perfumes and Incense in Ancient Egypt" The J ournal of Egyptian Archaeology, Vol. 16, No. 1/2, 1930, 41-53.

http://en.wikipedia.org/wiki/Islamic_civilization

Science, Technology and Innovation (STI) System in Egypt; http://www.asrt.sci.eg/ar/pdf/ASRTBooklet.pdf

http://en.wikipedia.org/wiki/List_of_universities_in_Egypt

https://www.zewailcity.edu.eg/the-city/city-overview/ 